\title{
Creation of Antibody Immunoassay Test Systems for Indication of Enteropathogenic Yersinia
}

\author{
$V$. Kuznetsova and Sergey Ivaschenko* \\ Saratov State Agrarian University named after N.I. Vavilova, 1, Teatralnaya Square, Saratov, 410600, \\ Russian Federation
}

\begin{abstract}
. 3 immunoassay test systems based on antibodies obtained as a result of immunization of rabbits with one of the antigens: disintegrated membranes (DM) Y. enterocolitica, DM Y. pseudotuberculosis and lipopolysaccharide Y. pseudotuberculosis were created. The best diagnostic properties were possessed by a test system based on antibodies to Y. pseudotuberculosis DM. It showed high titers of antibodies to various serovars of Y. pseudotuberculosis (1:25600-1:51200), incl. to microbe strains isolated from farm animals, and low titers to Y. enterocolitica (1:200). In the accumulation media with pig excrements seeded with Yersinia, the experimental test system detected Y. pseudotuberculosis already on the 3rd day of "cold enrichment" provided that 50 or more Yersinia cells per $\mathrm{ml}$ were inoculated into the accumulation medium together with excrements.
\end{abstract}

\section{Introduction}

The pseudotuberculosis microbe is secreted from pigs, cattle, sheep, goats, deer, monkeys, migratory birds $[1,2,3,4,5]$. For the eastern part of Europe, circulation in pigs is characteristic: O:3 serovars of the pseudotuberculosis microbe $(100 \%$ of the isolated cultures), for the central part - O:3 (60\%), O:1 (20\%), O:2 (20\%), for the southern part O:1 (60\%), O:3 (20\%), for England - O:3 (34 \%), O:1 (26\%), O:2 (24 \%) [6, 7, 8].

Obtaining a pure culture of the causative agent of pseudotuberculosis from animal excrements is associated with difficulties due to the strong contamination of the test material with extraneous microflora. To get rid of them it is possible using "cold accumulation" of Yersinia on "poor" liquid nutrient media, followed by sowing on dense combined nutrient media with selective and differential diagnostic properties. The effectiveness of combined media may vary. For example, when examining excrements, the diagnostic efficiency of Endo medium is $11 \%$, McConkey medium - 33\%, Serov medium $-42 \%$, SBTS $-81 \%[9,10]$.

The detectability of Yersinia in infected material can be increased using express diagnostic methods at the stage of reseeding from accumulative to combined nutrient media. Currently, to detect the causative agents of intestinal yersiniosis and

* Corresponding author: ivashenko-sv@mail.ru 
pseudotuberculosis, such express diagnostic methods as EIA (solid-phase indirect enzymelinked immunosorbent assay on tablets), polymerase chain reaction, coagglutination reaction, latex agglutination reaction, and the method of fluorescent antibodies are used. The most promising in this regard is EIA. Currently Federal State Institution of Science Pasteur Research Institute of Epidemiology and Microbiology, a commercial enzyme-linked immunosorbent assay for Y. pseudotuberculosis O:1 serovar is produced, which is based on lipopolysaccharide (LPS) and has a sensitivity of 105 cells $/ \mathrm{ml}$ and an efficiency of 70.2-81.1\% $[9,10]$.

However, our earlier studies established the presence of serovars of the pseudotuberculosis microbe in the excrements of sick young farm animals $0: 3$ and $0: 4$ [1], which requires the development of a test system that allows detecting a wider range of serovars of Yersinia pseudotuberculosis (Y. pseudotuberculosis). We attempted to create such a test system based on antibodies obtained as a result of hyperimmunization of rabbits with disintegrated membranes (DM) of Y. pseudotuberculosis and Yersinia enterocolitica (Y. enterocolitica), and Y. pseudotuberculosis LPS also.

\section{Methods}

DM and LPS were isolated from the museum strains Y. pseudotuberculosis III O: 3 serovars and Y. enterocolitica 66-82 0:3 serovars obtained from collection of pathogenic microorganisms Federal Government Health Institution RosNIPCHI Microbe. The bacteria were cultivated on mesopatamia agar for 2 days at the temperature of $24{ }^{\circ} \mathrm{C}$.

To obtain Y. pseudotuberculosis DM and Y. enterocolitica DM, the washed bacterial suspension was treated with an ultrasonic disintegrator. Then, partially destroyed cell membranes were separated from the cytoplasm and periplasm by centrifugation. The obtained cell membranes were destroyed to molecules with sodium dodecyl sulfate, from which they were subsequently freed by dialysis in running water.

LPS was isolated from acetone-dried cells of a pseudotuberculosis microbe with hot $45 \%$ aqueous solution of phenol without separation of layers [11]. Protein impurities were precipitated from the LPS solution by adding $40 \%$ trichloroacetic acid to a final $\mathrm{pH}$ value of 2.7 .

Rabbits were immunized subcutaneously along the back at 3-4 points in a volume of $1 \mathrm{ml}$ of a mixture of antigen and adjuvant. During immunization, the ratio of the adjuvant to the antigen solution was $1: 1$. DM was injected into the rabbit in the amount of $2 \mathrm{mg}$, and LPS - in the amount of $0.25 \mathrm{mg} .1 \%$ solution of polyazolidine ammonium modified with iodine hydrate ions (PAAG) was used as an adjuvant. 5 immunizations were carried out with an interval of 2 weeks. Blood for the study was taken from the ear vein in a volume of $5 \mathrm{ml} 14$ days after the last immunization.

The enzyme-linked immunosorbent assay was performed in an indirect version on plates [12].

$10 \%$ suspension of pig excrements taken at the time of a pig's bowel movement was seeded with 24-hour agar cultures of Y. enterocolitica or Y. pseudotuberculosis, and then added to the accumulation media: phosphate-buffered saline (PBS) $\mathrm{pH}=7.6-7.8$ and $1 \%$ buffered peptone water (BPW), so that the concentration of Yersinia in the accumulation media was $5 \times 105,5 \times 103,50$ cells $/ \mathrm{ml}$. Accumulation media with inoculations were incubated at $4{ }^{\circ} \mathrm{C}$ for 6 days. The study of media in EIA was carried out on the 3rd and 6 th days of "cold enrichment" of crops. To indicate Yersinia, part of the contents of the test tube, after mixing the medium, was introduced into the well of the plate and treated with $1 \%$ formalin for 4 hours.

Commercial antibodies were represented by pseudotuberculosis and intestinal yersinia O:3 sera attached to diagnostic kits for the indirect hemagglutination reaction (IHT). 
To determine the specificity of the obtained sera, microbial strains $Y$. pseudotuberculosis I, III, IV, V (O:1, O:3, O:4, O:5 serovars, respectively), Y. enterocolitica 66-82, 383 (O:3, O:9 serovars, respectively), from the museum collection of pathogenic microorganisms of Federal Government Health Institution RosNIPCHI Microbe, as well as Y. pseudotuberculosis strains 13, 40, 67 (O:3 serovars) isolated from calves, and Y. enterocolitica strains 12, 58 ( O:3 serovars) isolated from piglets. The bacterial cultures were washed, treated with formalin, and suspensions were prepared with a concentration of 109 microbial bodies/ml according to the turbidity standard.

\section{Results}

3 enzyme-linked immunosorbent assay systems were created based on antibodies to $\mathrm{Y}$. enterocolitica DM (Y. e.DM), Y. pseudotuberculosis DM (Y.p. DM), and Y. pseudotuberculosis LPS (Y.p. LPS). The sensitivity and specificity of the created test systems were studied in reaction with whole cells of Y. pseudotuberculosis and Y. enterocolitica. In the experiment, we used museum strains of Yersinia of various serovars obtained from the collection of pathogenic microorganisms of the Federal State Institution of Healthcare of the Russian Federation Microbe, as well as strains of Yersinia isolated from young farm animals. As a control, EIA was performed with commercial sera extracted from IHT kits. The test results are shown in Table 1.

An enzyme-linked immunosorbent assay based on antibodies to Y. enterocolitica DM showed generic specificity with museum strains of Yersinia and weakly interacted with Y. pseudotuberculosis strains isolated from farm animals, which makes it impossible to use it for diagnostic purposes. The test system using antibodies to LPS Y. pseudotuberculosis also cannot be used for diagnostics, because is weakly sensitive. A high sensitivity and species specificity with all strains of the pseudotuberculosis microbe was shown by an enzyme immunoassay based on antibodies to DM Y. pseudotuberculosis. Rabbit hyperimmune blood serum used in this test system is 16 times more active than commercial pseudotuberculosis serum. Therefore, the enzyme-linked immunosorbent assay based on antibodies to DM Y. pseudotuberculosis was chosen by us for further research as the most promising.

At the second stage of testing, we determined the possibility of using the selected test system to indicate the causative agent of pseudotuberculosis in the accumulation media on the 3rd and 6th days of "cold enrichment". We used two storage media: $1 \%$ BPW and PBS. Various amounts of Yersinia were preliminarily introduced into the media: $5 \times 105,5 \times 103$, 50 cells $/ \mathrm{ml}$, as well as pig excrements. The diagnostic serum in the test system was used in dilutions of 1:200 and 1:1600 to establish the effect of the concentration of antibodies on the efficiency of the test system. To assess the increase in the number of Yersinia in the process of "cold enrichment", the studies were carried out with two fold dilutions of the accumulation media from 1:2 to 1:256. The results of the experiment are presented in Table 2.

As can be seen from Table 2, after adding 50 or more cells $/ \mathrm{ml}$ of Y. pseudotuberculosis to the accumulation medium, already on the 3rd day of "cold enrichment", the test system detects the presence of these bacteria in the medium. This amount of microbe introduced into the medium corresponds to $5 \times 103 \mathrm{Y}$. pseudotuberculosis cells per 1 gram of animal excrements. Wherein, the test system does not detect Y. enterocolitica cells, confirming its species specificity. Extraneous microflora in pig excrements does not significantly hinder the process of displaying Yersinia with this test system. The limiting dilution of the diagnostic serum in the test system is 1:1600. The process of accumulation of Yersinia and extraneous microflora proceeds more intensively on the more nutrient medium of the BPW. 
Table 1. Results of determining the sensitivity and specificity of enzyme-linked immunosorbent assay systems with whole Yersinia cells.

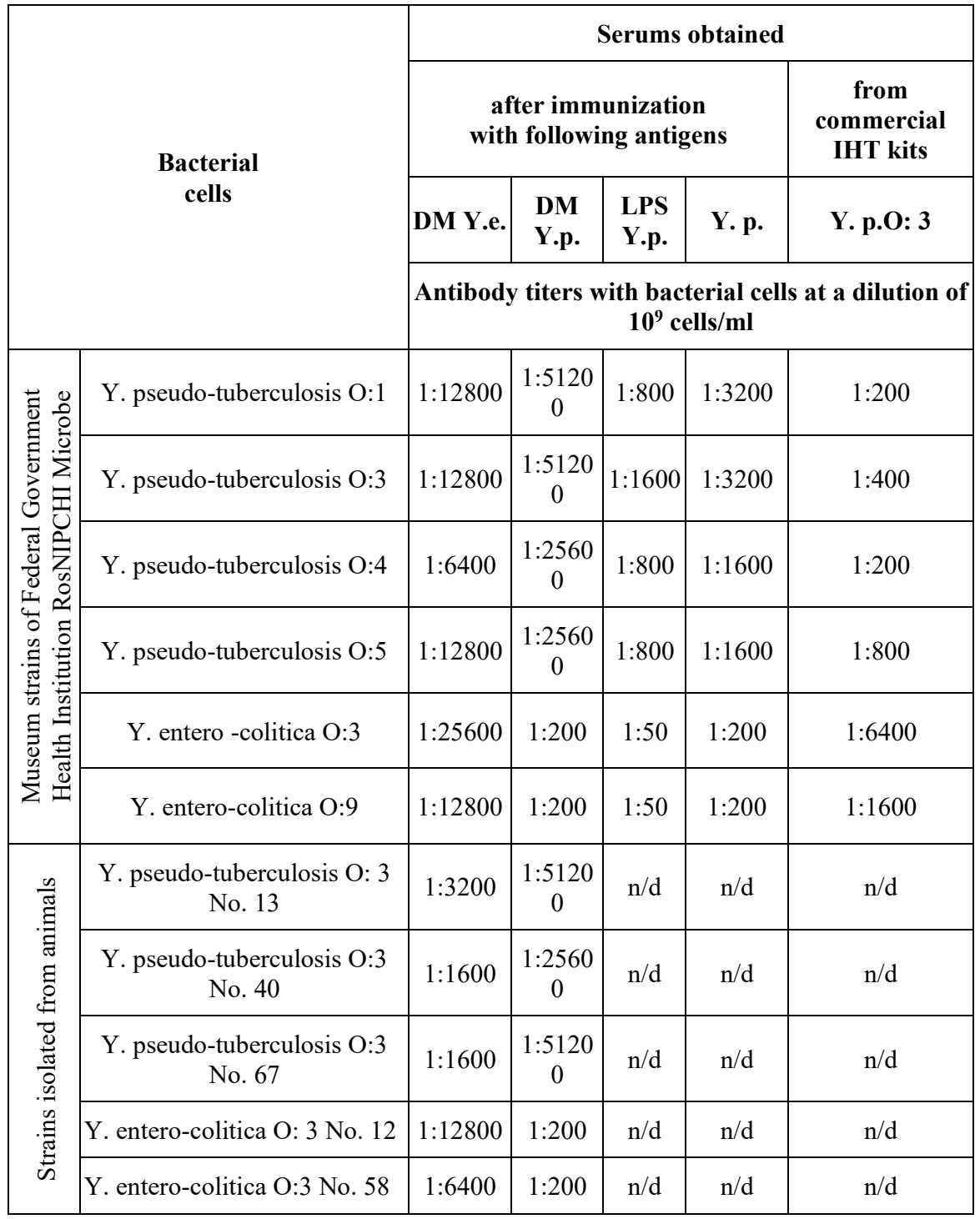

Note: "n/d" - there is no data

Table 2. Sensitivity of the experimental enzyme-linked immunosorbent assay with storage media on the 3rd and 6th days of "cold enrichment" of their Y. enterocolitica and Y. pseudotuberculosis.

\begin{tabular}{|c|c|c|c|c|}
\hline \multirow{4}{*}{$\begin{array}{l}\text { Number of } \\
\text { bacteria } \\
\text { introduced } \\
\text { in the } \\
\text { environment } \\
\text { of }\end{array}$} & \multicolumn{4}{|c|}{ Accumulation media } \\
\hline & \multicolumn{2}{|c|}{$1 \% \mathrm{BPW}$} & \multicolumn{2}{|c|}{ PBS } \\
\hline & \multicolumn{4}{|c|}{ enrichment time, days } \\
\hline & 3 & 6 & 3 & 6 \\
\hline
\end{tabular}




\begin{tabular}{|c|c|c|c|c|c|c|c|c|c|}
\hline \multirow{3}{*}{\multicolumn{2}{|c|}{ accumulation }} & \multicolumn{8}{|c|}{$\begin{array}{l}\text { dilution of pseudotuberculosis serum, } \\
\text { used to indicate Yersinia in environments }\end{array}$} \\
\hline & & $\begin{array}{c}1: 20 \\
0\end{array}$ & $\begin{array}{c}1: 16 \\
00\end{array}$ & $\begin{array}{c}1: 20 \\
0\end{array}$ & $\begin{array}{c}1: 160 \\
0\end{array}$ & $1: 200$ & $\begin{array}{c}1: 160 \\
0\end{array}$ & $1: 200$ & $\begin{array}{c}1: 160 \\
0\end{array}$ \\
\hline & & \multicolumn{8}{|c|}{$\begin{array}{c}\text { medium dilutions that showed a positive result with } \\
\text { pseudotuberculosis serum }\end{array}$} \\
\hline \multirow{3}{*}{$\begin{array}{c}\text { Y.p } \\
\text { seud } \\
\text { o- } \\
\text { tube } \\
\text { rcul } \\
\text { osis }\end{array}$} & $5 \times 10^{5}$ & $1: 16$ & $1: 4$ & $1: 64$ & $1: 16$ & $1: 8$ & $1: 2$ & $1: 32$ & $1: 8$ \\
\hline & $5 \times 10^{3}$ & $1: 8$ & $1: 2$ & $1: 32$ & $1: 8$ & $1: 4$ & - & $1: 16$ & $1: 4$ \\
\hline & 50 & $1: 4$ & - & $1: 16$ & $1: 2$ & $1: 2$ & - & $1: 8$ & - \\
\hline \multirow{3}{*}{$\begin{array}{c}\text { Y. e } \\
\text { nter } \\
\text { o- } \\
\text { colit } \\
\text { ica }\end{array}$} & $5 \times 10^{5}$ & - & - & $1: 4$ & - & - & - & - & - \\
\hline & $5 \times 10^{3}$ & - & - & $1: 2$ & - & - & - & - & - \\
\hline & 50 & - & - & - & - & - & - & - & - \\
\hline \multirow{2}{*}{$\begin{array}{l}\text { Cont } \\
\text { rols }\end{array}$} & $\begin{array}{c}\text { witho } \\
\text { ut } \\
\text { excre } \\
\text { ments } \\
*\end{array}$ & $1: 32$ & $1: 8$ & $1: 128$ & $1: 32$ & $1: 8$ & $1: 2$ & $1: 32$ & $1: 8$ \\
\hline & $\begin{array}{c}\text { witho } \\
\text { ut } \\
\text { Yersi } \\
\text { nia }\end{array}$ & - & - & - & - & - & - & - & - \\
\hline
\end{tabular}

\section{Discussion}

It can be seen from the studies that we managed to obtain high titers of specific antibodies in hyperimmune sera using a polyelectrolyte compound as an adjuvant. Compounds of this group have an immunostimulating effect and do not damage tissues at the injection site.

It shall also be noted that objective results of testing the specificity of veterinary antibody preparations can be obtained only on Yersinia cultures isolated from animals, because the source of Yersinia's emission can influence the test results. In addition, the museum test strains of Yersinia also lose some of the antigens during storage and cannot fully characterize the serum.

When choosing a liquid enrichment medium, in our opinion, it is necessary to pay attention to the possibility of reproduction of extraneous microflora in it, which will subsequently complicate the isolation of a pure culture of Yersinia. The most nutritious and less promising in terms of this parameter is $1 \% \mathrm{BPW}$.

We believe that at the laboratory stage of the study we were able to determine the most promising antibody preparation and, on its basis, to design an enzyme-linked immunosorbent assay that allows for indication of enteropathogenic Yersinia in 
accumulation media with pig excrements. Further study involves studying the effectiveness of the created test system on farm animals.

\section{Conclusion}

An enzyme-linked immunosorbent assay based on antibodies to Y. pseudotuberculosis DM showed species specificity and high sensitivity to Y. pseudotuberculosis cells.

The number of pseudotuberculosis bacteria introduced into the accumulation medium for confident indication by the enzyme-linked immunosorbent system on the 3rd day of "cold enrichment" was 50 cells $/ \mathrm{ml}$, which corresponds to the number of $5 \times 103$ Yersinia cells per gram of pig excrements.

\section{References}

1. S. V. Ivaschenko, A. A. Scherbakov, Materials of the International scientific and practical conference (Moscow, Izograf, 2006)

2. S. Zhang, Z. Zhang, S. Liu, W. Bingham, F. Wilson, J. Vet. Diagn. Invest., 20 (2008)

3. Y. M. Seimija, K. Sasaki, C. Satoh, M. Takahashi, G. Yaegashi, H. Iwane, J. Vet. Med. Sci., 67 (2005)

4. T. Niskanen, J. Waldenstrom, M. Fredriksson-Ahomaa, B. Olsen, H. Korkeala, Appl. Environ. Microbiol., 69 (2003)

5. T. Iwata, Y. Une, A. T. Okatani, Y. Kato, A. Nakadai, K.I. Lee, M. Watanabe, T. Taniguchi, A. E. Elhelaly, Y. Hirota, H. Hayashidani, Vet. Microbiol, 129 (2008)

6. P. O. Martinez, M. Fredriksson-Ahomaa, Y. Sokolova, M. Roasto, A. Berzins, H. Korkeala, Foodborne Pathog. Dis., 6 (2009)

7. P. O. Martinez, M. Fredriksson-Ahomaa, A. Pallotti, R. Rosmini, K. Houf, H. Korkeala, Foodborne Pathog. Dis., 8 (2011)

8. P. O. Martinez, S. Mylona, I. Drake, M. Fredriksson-Ahomaa, H. Korkeala, J. E. Corry, Int. J. Food Microbiol., 139 (2010)

9. I.A. Shurygina, M. V. Chesnokova, V. T. Klimov, I. V. Malov, A. S. Maramovich (Novosibirsk, Nauka, 2003)

10. G. Ya. Tseneva (St. Petersburg, St. Petersburg Research Institute of Epidemiology and Microbiology named after Pasteur, 1997)

11. V. A. Kulshin, A. P. Yakovlev, S. N. Avaeva, B. A. Dmitriev, Mol. genetics, microbiol. and virusol, 5 (1987)

12. P. Hornbeck, S. E. Winston, S. A. Fuller, Current Protocols in Molecular Biology, 15 (2001) 